\title{
Science in Society: Toward Receptor- Oriented Integrative Risk Governance in Artificial Turf Risk Case
}

\author{
Seohyun Park \\ Department of Environmental Engineering, \\ Chonbuk National University, Jeonju, Korea
}

Corresponding author: Seohyun Park

Received: Sep 09, 2015, Accepted: Oct 31, 2015, Published: Nov 07, 2015

Department of Environmental Engineering, Chonbuk National University, Jeonju, Korea

\section{Introduction}

During last decades our global societies have faced many complicated environmental and health problems. It is extremely difficult to find solutions due to dilemmatic socio-cultural conditions, such as, scientific uncertainties, income inequality, social conflicts, and resource depletion. These problems are intertwined each other and possibly studied under categories of "environmental justice" and "sustainability." The fundamental underpinning of environmental justice and sustainability is to protect vulnerable social groups who have a lack of capacity to cope with a threat from environmental and social changes [1].

Children are particularly the most vulnerable and sensitive group to chemical exposures, because they are at different stages of development physically and mentally. In this short paper, I briefly introduce, first, problematic stories of artificial turfs (AT) potentially causing environmental and health problems and, second, wish to address the important role of the receptororiented integrative risk governance model in dealing with the complicated risk.

\section{Artificial Turf Risk Cases}

In October 8th, 2014, one of the U.S. national broadcasters, NBC News reported about a potential link between cancer risks and AT fields [2]. On the show, a head coach engaged for the women's soccer team in the University of Washington, Amy Griffin, provided her list in which contained the content that young goalkeepers among other soccer players particularly had a high percentage of various types of illnesses including non-Hodgkin lymphoma, leukaemia, and other cancers. She suspected that AT could be a cause of such health problems that the players have gotten, since these young players are the group of people who highly frequently contact with AT fields, every time playing games and training. Debates occur with a lack of scientific certainties in relation to health risks of AT.

Some toxicologists and engineering researchers concluded that AT has no serious health risks [3-5]. By contrary Environment and Human Health, INC (EHHI) argued that it is necessary to conduct more evaluation studies particularly whether synthetic turf can cause any harmful effects to children [6]. EHHI also addressed that seohyun.park@gmail.com

Tel: 82104055 2796, 82632702445

Fax: 82632702449

Citation: Park S. Science in Society: Toward Receptor-Oriented Integrative Risk Governance in Artificial Turf Risk Case. J Med toxicol clin forensic med. 2015, 1:1.

multiple tests should be conducted about levels of carcinogenic polycyclic aromatic hydrocarbons (PAHs) and also about various anti-microbial that can cause health issues. On the top of that, this institute shed light on various aspects of AT risks: for example, whether these products have economically and environmentally benefits over other alternatives such as natural grass fields and organic grass fields [7].

In Korea playgrounds and sport fields have drastically been changed to AT since 2005 with significant amounts of budgets invested by the Korean Metropolitan and Provincial Offices of Education co-sponsored with local governments. After a decade the replacement time of AT infill products comes, as persisting period ending, people's concerns toward health risks associated from AT playgrounds drastically increase. It is proven that the flow of the risk information grows since 2012. In addition, a variety of risk perceptions appear in the society among stakeholders or actors including parents, students, teachers, governmental agencies of environment and education, local institutes, nongovernmental organization groups, the green party, industrial sectors, scientists, and technical experts [8]. People have polarized perceptions and different opinions about AT risks and associated alternatives. Special note is necessarily addressed that students who are supposed to be major affected groups from AT are likely to have lower perceptions toward health risk from their playgrounds. 


\section{Conclusion}

\section{Toward Receptor-Oriented Integrative Risk Governance}

According to the stories of artificial turf risks both in the U.S. and Korea, it is difficult to make a desirable decision till having a scientific certainty. This issue lies on policy of the precautionary principle that can provide guidelines of decision-making and actions in response to serious risks anticipated under a lack of scientific consensuses. In this regard, it is necessary to bring the receptor-oriented integrative risk governance model. Receptororiented approach enables to focus on vulnerable individual risk receptors or subjective risks [9]. Therefore, governments should take consideration of young people and goalkeepers in the assessment of health risk. Risk governance is established for desirable and fair risk management and communication by involving various actors and stakeholders, two-way risk communication processes, as well as, regulatory approaches and market structures [10].

Science-centered policy has its limitation in dealing with complicated environmental health risk due to inherent segregations among disciplinary frameworks and methods. However, our human body systems are not separated from their outer environmental systems. Therefore, receptor-oriented and integrative risk governance model can make it possible to evaluate contextual factors of risks and risk receptors, and to lead to realistic health care for children. I argue that this model is necessarily this model is necessarily the direction in the area of medical toxicology as well as environmental health policy. 


\section{References}

1 Boone CG (2010) Environmental justice, sustainability and vulnerability. International Journal of Urban Sustainable Development 2:135-40.

2 How Safe Is the Artificial Turf Your Child Plays On? (2014). NBC News.

3 Beausoleil M, Price K, Muller C (2008) Chemicals in Outdoor Artificial Turf: A Health Risk For Users? BISE 19: 4.

4 Kim H-H, Lim Y-W, Kim S-D, Yeo I-Y, Shin D, et al. (2012) Health Risk Assessment for Artificial Turf Playgrounds in School Athletic Facilities: Multi-route Exposure Estimation for Use Patterns. Asian Journal of Atmospheric Environment 6: 206-21.

5 Vidair C (2010) Safety Study of Artificial Turf Containing Crumb Rubber Infill Made From Recylced Tires: Measurements of Chemicals adn Prticulates in the Air, Bacteria in the Turf, and Skin Abrasions Caused by Contact with the Surface. Office of Environmental Health Hazard Assessment Pesticide and Environmental Toxicology Branch.

6 Connecticut's Artificial Turf Study's Risk Estimates Were Modified to Avoid Alarming the Public (2010) Environment and Human Health. INC.

7 Brown DR (2007) Artificial Turf: Exposures to Ground Up Rubber Tires - Athletic Fields, Playgrounds, Garden Mulch.

8 Artificial Turf Wins "Covenience rather than Risk" (2015) Media Jeju.

9 Ha E (2014) Public Policy on Children's Environmental Health in Asia. Textbook of Children's Environmental Health. Oxford University Press, New York.

10 Renn O, Graham P (2005) Risk Governance: Toward and Integrative Approach. The International Risk Governance Council. 